\title{
Understanding digital transformation in the manufacturing industry: a systematic literature review and future trends
}

\author{
Yasser Omar Abdallah ${ }^{1 *}$ (D), Essam Shehab ${ }^{2}$, Ahmed Al-Ashaab ${ }^{3}$ \\ ${ }^{1}$ School of Aerospace, Transport \& Manufacturing, Cranfield University, Cranfield, Bedford, UK. \\ ${ }^{2}$ School of Engineering and Digital Sciences, Nazarbayev University, Nur-Sultan, Kazakhstan \\ ${ }^{3}$ School of Aerospace, Transport \& Manufacturing, Cranfield University, Cranfield, Bedford, UK
}

\begin{abstract}
Digital transformation is one of the most evolving areas both in the research literature and in industrial applications. No doubt that this process will be crucial in the survival of any manufacturing organisation in the future, especially during the current COVID-19 crisis. This paper aims to present a review of the concept in the manufacturing industry through the literature currently available on the topic. The literature was classified, and the results of each study were analysed. From this review, six critical findings have been identified in this paper. First, this paper proposes a definition of Digital Transformation and its concept development in the manufacturing industry. Moreover, significant challenges that exist in the manufacturing industry in the implementation of the digital transformation process have been classified as well as the major enabling technologies that help to implement the Digital Transformation. Finally, the benefits of implementing Digital Transformation in the manufacturing industry and its impact on the manufacturing ecosystem have been highlighted. Following a comprehensive review of the literature, future research directions are formulated to identify abundant research opportunities.
\end{abstract}

Keywords: digital transformation, manufacturing, literature review.

\section{Introduction}

In today's exponential change towards digital technologies and the utilisation of these technologies in different fields and sectors, organisations change the way of doing business towards achieving their goals. This change only will not affect the way of operations inside the organisation but also affects the way of reaching the customer and the way of providing the goods and services produced (Anwer et al., 2019a). Manufacturing Industry, as one of the most critical sectors inside any economy, is greatly affected by the digitalisation of manufacturing processes through the development of new technologies that can be used to enhance the productivity of the operations processes inside any manufacturing organisation (Chryssolouris et al., 2009a).

Digital Transformation (DT) in the manufacturing industry plays a vital role in keeping the organisation into the pace of competition. The only way of sustainability now inside any competitive market is by transforming business processes into a digital one. From here comes the importance of Digital Transformation of existing firms to cope with the native digital organisations that appeared in the past 10-15 years (Horvath et al., 2018).

Although Digital Transformation (DT) has been much emphasised in the academic research in the past few years, there is ambiguity about this term regarding its definition, framework, and challenges, especially in the manufacturing industry (Vial, 2019). There is no one clear definition of what Digital Transformation is (De Carolis et al., 2018; Ng et al., 2019; Nwankpa \& Roumani, 2016; Zangiacomi et al., 2020). In addition, the authors that tried to define Digital Transformation generally reflects the background and the perspective seen by its authors (e.g. financial sector and government domain). Moreover, there is no sufficient literature review studies had been taken to address this concept in the manufacturing industry (Anwer et al., 2019b; Laird, 2017; Li et al., 2018).

For all of this ambiguity surrounding this term especially in the manufacturing industry, a systematic literature review is needed to gain more insights of the term and open new paths to study and analyse this term as well as explore new ways for successfully implementation in manufacturing industry. 
This paper proposes a definition and the main challenges of Digital Transformation in the manufacturing industry. It also provides an extensive systematic literature review of this term inside the manufacturing industry and Digital Transformation processes.

\section{Research outline}

\subsection{Aim, scope, and research questions}

This research aims to analyse and summarise the literature currently available on Digital Transformation (DT). To achieve more valid research on the concept, the focus of this study has been on articles that are concentrated on DT within the manufacturing industry. This scoping process includes a definition of several criteria for inclusion and exclusion of sources, relevant fields of study, relevant sources, as well as a search term to work as criteria to categorise these sources.

Regarding the research questions, this research has been developed to address the following questions:

1. What is Digital Transformation and how it is defined in the manufacturing industry?

2. What are the main barriers to implementing Digital Transformation in the manufacturing industry?

3. How can DT affect the manufacturing ecosystem?

4. What are the main benefits for the implementation of DT inside the manufacturing firms?

5. Where are the drawbacks of the existing literature and points of future research in this regard?

\subsection{Search methodology}

To begin, a search on online databases about "Digital Transformation" only has been initiated. This search gave us a quite understanding about how this term is searched in different fields like Information Systems, Healthcare, Management, Manufacturing. The number of findings in these resources showed considerable interest in this concept, especially in the last few years in all varied disciplines.

This research is focused on sources from manufacturing literature to maintain a certain degree of consistency with regards to the specific topics of interest while ensuring that the research sample size would remain considerable. WoS (Web of Science), EBESCO (business source complete), ScienceDirect, and Scopus had been chosen to filter the research. WoS has the leading journals in the digital manufacturing theme. Business source complete had been investigated to add other journals that are not focused on manufacturing but have journals that talk about Digital Transformation from a business perspective. ScienceDirect and Scopus for validation and ensuring that every journal that is not in WoS or EBESCO will be considered into the research.

Criteria for exclusion included: works in progress; panel introductions; sources not available in English; unavailable full papers; papers before 2005. This study's time frame is to address Digital Transformation in the present and future direction. In the initial search, papers from the ' 80 s and '90s that talk about Digital Transformation had been found but from old or obsolete technology. Therefore, to make the research more reliable, papers that age 15 years old or less were selected. Moreover, papers that are not related to the manufacturing industry had been excluded to keep this field's scope. The reason for this that Digital Transformation has different meanings according to the sector it is applied in. For example, Digital Transformation in the banking sector has a different perspective and more service-focused than when applying the same concept in the manufacturing industry.

From the initial search, there are interchangeable words with Digital Transformation like Digital Disruption or Digitalisation of Manufacturing had been noticed (Peillon \& Dubruc, 2019; Tolkachev et al., 2020; Zangiacomi et al., 2020), so these words had been identified that could be linked to Digital Transformation like Digital disruption, Digitalisation and Industry 4.0.

The outlined research databases then searched using a combination of these keywords. The list then refined to remove duplicates, and the titles were checked to ensure the paper's consistency with this review. Then the abstracts also checked to before selecting the publication for a full review.

\subsection{Search results}

In the beginning, 90 articles had been found from the search terms. Then, these articles were carefully analysed and reviewed to assess their relevance to the search aim. After this reviewing, these articles had been filtered to produce 42 articles that were directly relevant to this research's aim. After cross-referring these papers, the research had ended up with 55 articles directly relevant to the research aim. Those selected papers were then carefully analysed to produce the following results. 


\section{Research findings}

\subsection{Definition of digital transformation}

According to the literature, few articles focus on defining what Digital Transformation is, especially in the manufacturing-focused papers, and there was an overlap between defining Digital Transformation and other related terms, for example, industry 4.0 or digital disruption. A summary of the definitions found in the literature are summarised in Table 1.

Table 1. Digital Transformation Definitions.

\begin{tabular}{cc} 
Definition & Author \\
\hline $\begin{array}{c}\text { Digital Transformation strategy is a blueprint that supports companies in governing the } \\
\text { operations after a transformation. }\end{array}$ & Cimini et al., 2017 \\
transformations that arise owing to the integration of digital technologies, as well as in their & \\
$\begin{array}{c}\text { Digital Transformation is defined as an organisational shift to big data analytics, cloud, mobile } \\
\text { and social media platform. Whereas organisations are continually transforming and evolving in } \\
\text { response to changing business landscape, Digital Transformation is the changes built on the } \\
\text { foundation of digital technologies, ushering unique changes in business operations, business } \\
\text { processes and value creation. }\end{array}$ & $\begin{array}{c}\text { Nwankpa \& Roumani } \\
\text { (2016) }\end{array}$ \\
$\begin{array}{c}\text { Digital Transformation is the profound and accelerating transformation of business activities, } \\
\text { processes, competencies, and models to fully leverage the changes and opportunities brought } \\
\text { by digital technologies and their impact across society in a strategic and prioritised way }\end{array}$ & Demirkan et al. (2016) \\
$\begin{array}{c}\text { Digital Transformation is a technology-induced change on many levels in the organisation that } \\
\text { includes both the exploitation of digital technologies to improve existing processes and the } \\
\text { exploration of digital innovation, which can potentially transform the business model }\end{array}$ & Berghaus \& Back (2016) \\
$\begin{array}{c}\text { The use of new digital technologies, in order to enable significant business improvements in } \\
\text { operations and markets such as enhancing customer experience, streamlining operations or } \\
\text { creating new business models }\end{array}$ & Paavola et al. (2017) \\
$\begin{array}{c}\text { Fundamental alterations in existing and the creation of new business models [...] in response } \\
\text { to the diffusion of digital technologies such as cloud computing, mobile internet, social media, } \\
\text { and big data. }\end{array}$ & Mittal et al., 2019 \\
$\begin{array}{c}\text { Digital Transformation is about adopting disruptive technologies to increase productivity, } \\
\text { value creation, and social welfare. }\end{array}$ & Cachada et al., 2019 \\
$\begin{array}{c}\text { Digital Transformation is a process that aims to improve an entity by triggering significant } \\
\text { changes to its properties through combinations of information, computing, communication, } \\
\text { and connectivity technologies. }\end{array}$ & Vial (2019) \\
\hline
\end{tabular}

From these carefully selected definitions, the following has been indicated:

- There are different perspectives of viewing Digital Transformation. One author defines it as a strategy; another defines it as a process; third defines it as a disruptive element. This variation comes from the ambiguity of this term so far. So, there is no clarity about what Digital Transformation is precisely (Castelo-Branco et al., 2019; Hartley \& Sawaya, 2019; Kolla et al., 2019; Tokody, 2018; Vial, 2019; Zangiacomi et al., 2020).

- Most of the authors use the term "Digital Technologies" in their definition which means that technology is a crucial element in the Digital Transformation in any industry specifically the manufacturing industry (Cachada et al., 2019; Dombrowski \& Fochler, 2018; Lee et al., 2011; Mittal et al., 2019)

- There are unclear terms such as social welfare or using specific examples that weaken the definition. Moreover, there is some circularity in the definition, for example, using the word transformation in the definition (Ananyin et al., 2018; Cimini et al., 2017; Ismagilova et al., 2019).

From the analysis of the concept and after reviewing these definitions, a conceptual definition of Digital Transformation had been constructed with the focus of manufacturing industry as follow:

Digital Transformation (DT) is a customer-centric mechanism that enables continuous improvement in the productivity of the manufacturing processes using advanced digital technologies such as cloud computing, Internet of Things, big data analytics, digital twin, artificial intelligence in all aspects of the organisation.

From this proposed definition, the following critical elements of this definition is illustrated as follows: 
- Customer-centric element: most of the previous definitions totally neglect the voice of the customer when talking about transformation processes. However, listening to the customer is very crucial in formulating the organisation Digital Transformation process to ensure that it will increase customer satisfaction and hence increase profitability (Dombrowski \& Fochler, 2018; Horvath et al., 2018; Laird, 2017).

- Continuity element: Digital Transformation is a process that never ends. As long as more technologies evolve and arise over time, Manufacturing organisations need to continually transform their business processes to cope with this technology advancement (Chryssolouris et al., 2009b; Heikkila et al., 2016; Tokody, 2018). It is not one-time planning and implementation, and manufacturing firms need to understand that element to remain competitive.

- Digital technologies element: the technology element in the Digital Transformation is crucial and selecting the most appropriate digital technologies that will adapt to the manufacturing theme is very critical in the success of the Digital Transformation process giving the cost of these technologies and the uncertainties that this technology will become obsolete over a short period.

- The organisation element: Digital Transformation process will not succeed without embedding it into all aspects of the organisation. This transformation requires integrating digital technologies into all aspects of the organisation to ensure that the human factor in the firm makes the best use of digital technologies to improve the productivity of manufacturing processes (Ananyin et al., 2018; Cimini et al., 2017; Demirkan et al., 2016; Rojo Abollado et al., 2017; Schallmo et al., 2017).

\subsection{Development of the Digital Transformation concept}

Digital Transformation term evolved through time. In the ' $70 \mathrm{~s}$ and ' $80 \mathrm{~s}$ of the last century, it could mean the use of computing inside the manufacturing firms. Now, it has a different and more generic definition. As in Figure 1, the development of this term was concluded into three main steps in the research literature as follows:

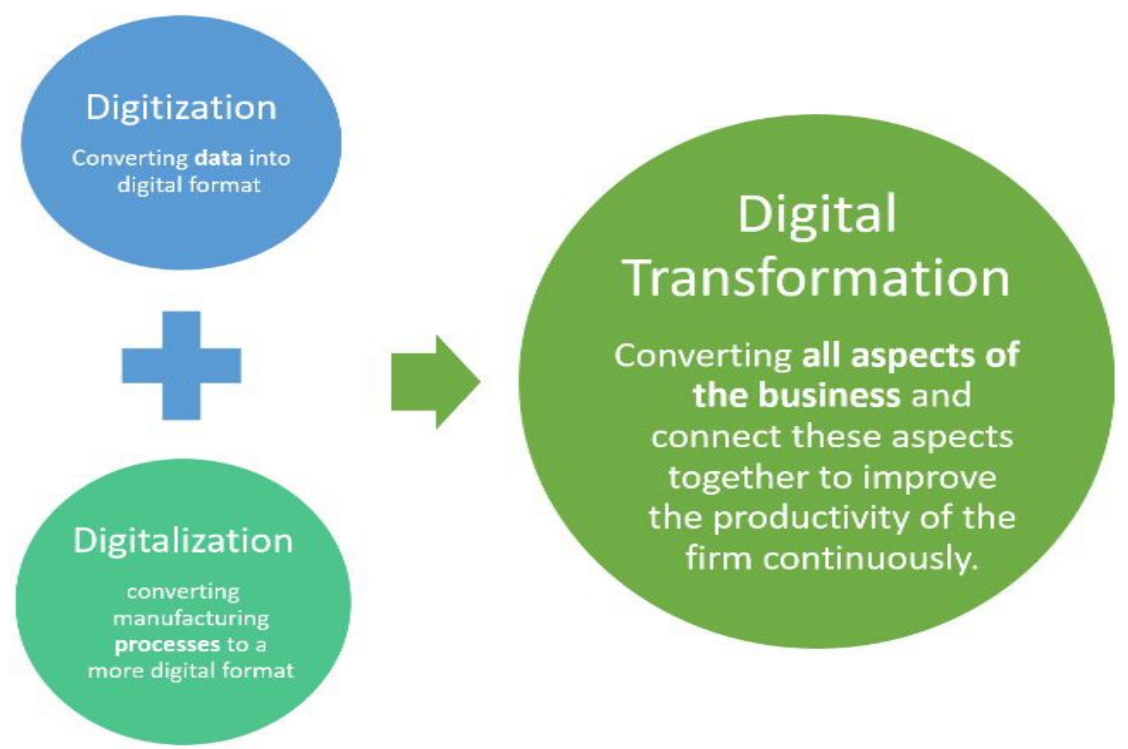

Figure 1. Evolution of Digital Transformation Term.

\section{Digitisation}

The oldest term in this area is Digitisation. According to Gartner IT glossary, it refers to "the conversion of analogue or physical information to a digital format" (Zangiacomi et al., 2020). This definition is like converting a paper instruction manual into a digital format. This process is the simplest way of transformation. It is just transforming the data from a paper-based into a more electronic-based. When converting the process as well as the information, here comes the role of Digitalisation (Nwankpa \& Roumani, 2016).

II. Digitalisation

Both terms are very close to each other. Most of the literature used them interchangeably. However, it is better to see them as a development of one term to another. Digitalisation could be defined as "the way in which many domains of social life are restructured around digital communication and media infrastructures" (Brennen \& Kreiss, 2016). This change happens when transforming the business processes into a more digital format. For example, using smart glasses to provide mechanics with a line of sight, digital instructions can improve efficiency and reduce errors. 


\section{Digital Transformation}

As stated earlier, the concept is not about technology, like the previous two concepts. It is about business processes, management styles, organisational culture, corporate strategy, and, most importantly, linking all of these together using digital technologies (Ismagilova et al., 2019). The goal of this is to bring meaningful outcomes to the organisation. Integration of different digitalisation initiatives, such as augmented reality guided instructions, 3D printed tools that have Internet of Things-enabled sensors connected with them can result in the fundamental transformation of the manufacturing process (Borangiu et al., 2019). So, both digitisation and digitalisation lead to Digital Transformation (Kutzner et al., 2018; Zangiacomi et al., 2020).

\subsection{Barriers to adopting Digital Transformation in the manufacturing industry}

By comparing traditional and digital organisations, later organisations can also grow their business more rapidly due to their high degree of flexibility to consumer needs and the adoption of fast-paced new technologies (Heavin \& Power, 2018).

However, the application of this transformation process is faced by many challenges and constraints in the small and medium enterprises (SMEs) only and on the large corporations (Heavin \& Power, 2018; Horvath et al., 2018). These challenges may differ from industry to industry. Moreover, the degree of the same challenges may also change over different industries (Zangiacomi et al., 2020).

After analysing the literature, the Digital Transformation process's significant challenges had been divided into four main categories (Figure 2): Skills Gap, The Adoption of New Technologies, Change Management Process, Innovation Policies and Procedures.

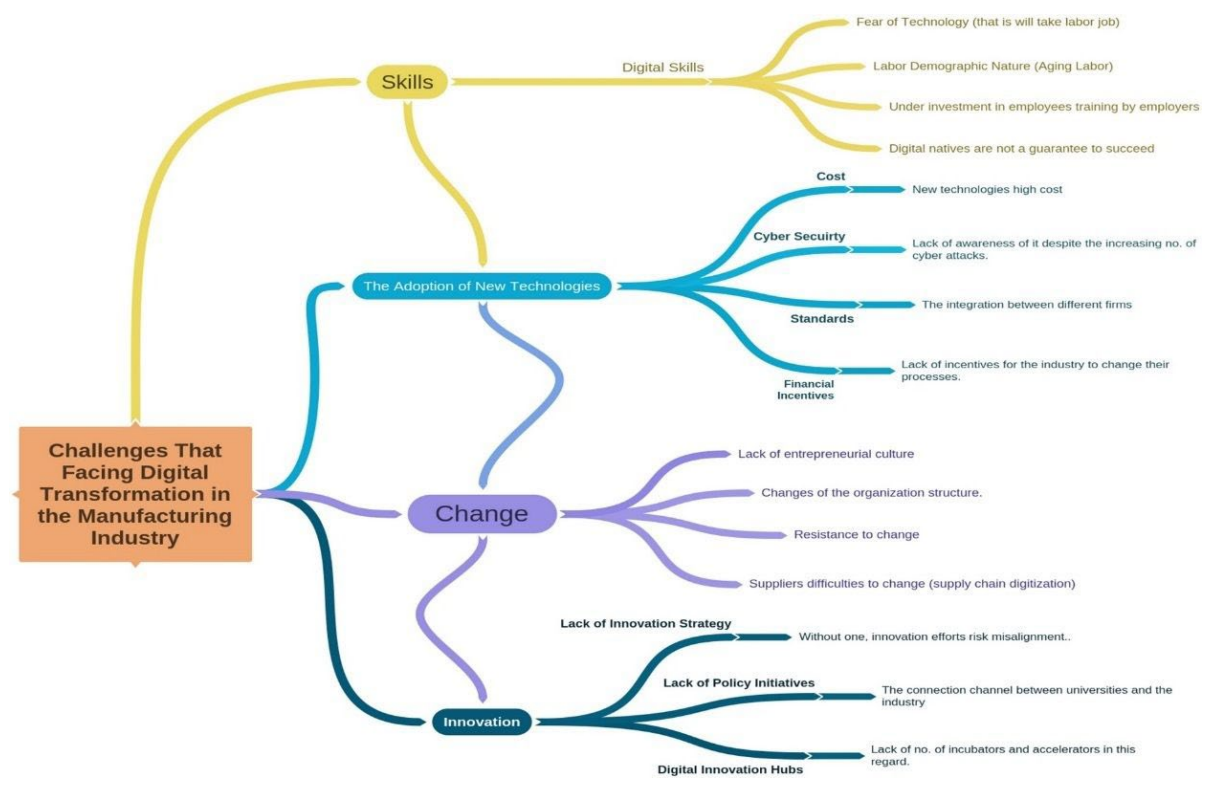

Figure 2. Challenges of Digital Transformation Implementation.

\subsubsection{Skills gap}

There is an apparent skills gap between the digital skills possess by the manufacturing organisations and what they want to keep up with the digital pace (Chryssolouris et al., 2009b; El Hamdi et al., 2020; Horvath et al., 2018). According to the SAP report in 2018 , there is a $20 \%-40 \%$ skills gap between what is needed and required. Moreover, in a recent study by Technical University Munich (TUM), 64\% of companies surveyed said that they do not have the people with the skills necessary for Digital Transformation (Peillon \& Dubruc, 2019). Digital skills become a necessity to implement Digital Transformation successfully, and the need for these kinds of skills will increase in the upcoming years (Kokolek et al., 2019; Nwankpa \& Roumani, 2016). Unfortunately, employers do not provide enough resources to train their employees. Another challenge in this regard is the fear of technology. Labour fear of technology will replace their jobs and resist this transformational place (Heavin \& Power, 2018). Nobody wants to lose his/her job in favour of technology or make a robot replace his/her job.

\subsubsection{The adoption of new technologies}

Adopting new technologies requires a risk-taking culture inside the organisation. This risk exists because it requires a high initial investment and long-term return. This type of culture called entrepreneurial culture (Ananyin et al., 2018). Manufacturing firms lack the awareness of this culture because businesses, in general, are 
risk-averse. They tend to invest in low-risk projects with a short-term return. This risk-aversion is shown in Made Smarter report in 2017, as stated that there is little investment in new technologies in the manufacturing industry, especially in the SMEs (Cozmiuc \& Petrisor, 2018).

Another threat in the digital world is cyber attacks. With the increasing number of attacks every day; businesses lose a lot of money and efforts to prevent them. The main problem in these types of attacks is that it is evolving and every day, new threats are being used to harness the business (Heikkila et al., 2016).

Another challenge is the cost of transferring data from old systems into new systems. Legacy systems become outdated, and no comply with the usage of new technologies. This transformation may cost much money and effort to do this in the right way (Castelo-Branco et al., 2019; Frank et al., 2019; Parra et al., 2019). Manufacturing firms need to decide whether to update their old systems or to buy a new updated system.

\subsubsection{Change management process}

Digital Transformation is a combination of disruptive technologies (Berghaus \& Back, 2016; Hausberg et al., 2019). This disruption makes it very hard to apply and use. Therefore, one of the most complicated challenges in manufacturing firms is the changing of its structure (Heavin \& Power, 2018). Changing the structure of any organisation is an arduous process and needs a lot of time and efforts to overcome the resistance of this change (De Carolis et al., 2018; El Hamdi et al., 2020; Loonam et al., 2018; Paavola et al., 2017).

Another challenge is the resistance of change for existing employees. Current employees used to work on old systems and old structures; they do not want to move from their comfort zones (Kunii \& Hasegawa, 2019; Laird, 2017; Rojo Abollado et al., 2017). This resistance requires managing the change process and unfreeze the status quo to make the required modifications.

\subsubsection{Innovation initiatives}

Innovation is a critical element in the success of Digital Transformation processes inside the manufacturing industry. On the organisation's strategic level, most firms lack the existence of innovation strategy (Tokody, 2018). On the national level, no innovation initiatives to occur in the manufacturing industry (Demirkan et al., 2016).

\subsection{Enabling technologies of digital transformation}

One of the critical determinants of the Digital Transformation process's success is the digital technologies applied in the manufacturing firm. Many researchers state different technologies used in the Digital Transformation process according to the organisation's field (De Carolis et al., 2018). Within the focus of this paper, the digital technologies applied in the manufacturing firms has been illustrated in Figure 3. All these technologies are linked together to achieve a more valid Digital Transformation process (Bai et al., 2020; Osterrieder et al., 2020)

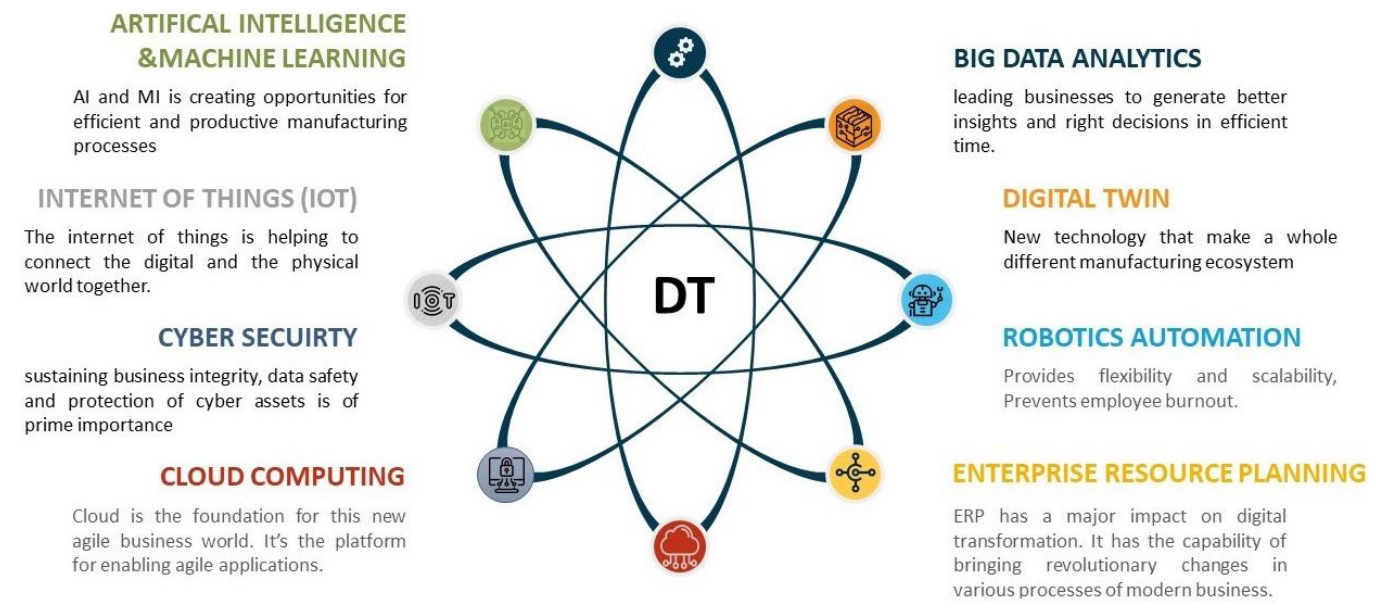

Figure 3. Enabling Technologies of Digital Transformation.

One of the most technologies that enable Digital Transformation inside any organisation is artificial intelligence and its various applications (Demirkan et al., 2016; Hartley \& Sawaya, 2019; Qi \& Tao, 2018; Ulas, 2019). With this technology, as well as machine learning, equipment becomes more efficient and effective in their operations as they become more aware of the processes and how to self-learn and solve any problems issued inside the production processes (Hartley \& Sawaya, 2019). 
IoT technology enables businesses to link the physical world with the digital world. It helps manufacturing firms gather more data from machines and equipment, and this help a lot in understanding the manufacturing problems and how to handle them more efficiently to make more productive operations (Borangiu et al., 2019; Cachada et al., 2019; CasteloBranco et al., 2019; Gökalp et al., 2017).

Moreover, one of the essential elements in the successful implementation of Digital Transformation is the organisation's digital world's security. As mentioned earlier, With the increasing number of cyber-attacks each day, cybersecurity technology becomes vital in any organisation today (Heikkila et al., 2016; Mittal et al., 2019; Tokody, 2018; Tolkachev et al., 2020). Manufacturing organisation need to build a robust cyber system to ease the accessibility of data and at the same time, make it secure enough from the digital attacks (Tokody, 2018).

Another matter also in this regard is data privacy, especially customer's data. If the customer feels that third parties are using his/her data, they will not use the organisation products or services anymore.

Cloud Computing is also one of the foundations of Digital Transformation. With the existence of agile applications and the need to access data anytime anywhere, the organisation need to have a robust cloud system that enables employees to work with it and have the accessibility of data necessary to perform their operations (Borangiu et al., 2019; CasteloBranco et al., 2019; Piccinini et al., 2015). Machine learning and IoT provide vast amounts of data about everything that happened in the factory. Big data analytics help provide great insights about these data and how to collect, analyse and organise these amounts of data to help the management take the right decisions promptly and provide new ways of innovation (Castelo-Branco et al., 2019; Paritala et al., 2017; Qi \& Tao, 2018).

Digital Twin is a new term that was first raised in 2003 and redefined in 2015 as part of the product lifecycle management is one of the most advanced technologies nowadays. With this digital technology, the organisation make a replica of its machines, systems, processes, or even products (Kritzinger et al., 2018; SME Media Staff, 2017). This replica enables the organisation for training purposes and how to handle manufacturing problems more efficiently.

Robots is one of the advanced technologies used inside the manufacturing firms to handle difficult tasks to reduce worker burnout and increase the factory's health and safety procedures. However, the manufacturing organisation must keep the right balance between robots and human power to ensure the agility of the processes and make the most of the firm machines (Agrawal \& Narain, 2018; Demirkan et al., 2016; Ulas, 2019).

ERP is a software toolkit that helps the organisation link all its various departments to help transfer the information vastly and in real-time. With the existing of a robust cloud system, Cloud ERP will be more efficient in data privacy and data transfer velocity instead of traditional ERP software(Lee et al., 2011).

\subsection{Benefits of implementing Digital Transformation}

Digital Transformation will have a massive impact on the business processes internally and externally from a business perspective. As mentioned earlier, this is a very long and hard to achieve journey, but once achieved the pattern to which that Digital Transformation is embedded inside the organisation manufacturing processes, the business will begin to reap its benefits (National Archives of Australia, 2011; Rojo Abollado et al., 2017). The literature mentioned many benefits for implementing Digital Transformation, summarised as Figure 4 shows. Additional discussion for each one of them in details is held in this section.

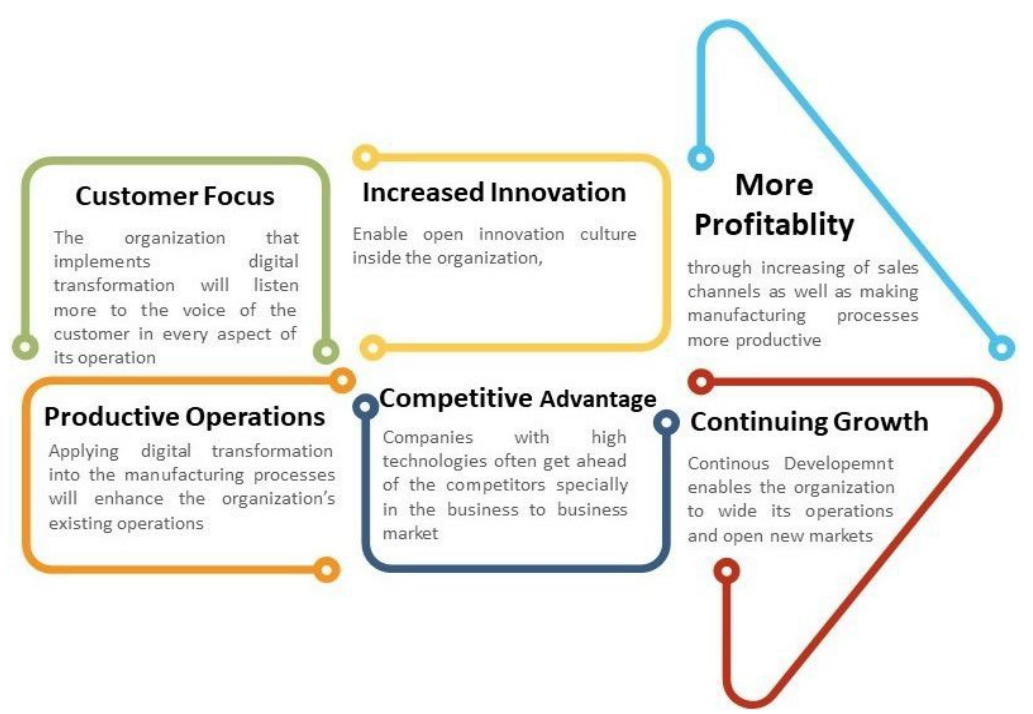

Figure 4. Benefits of Digital Transformation Implementation. 
These benefits depend on each other, so it is an accumulated step-by-step advantages that depend on Digital Transformation implementation.

As stated in the proposed definition of Digital Transformation, it is a customer-centric mechanism. Therefore, the organisation implementing Digital Transformation will listen more to the voice of the customer in every aspect (Cozmiuc \& Petrisor, 2018; Drake, 2019; Ismagilova et al., 2019; Laird, 2017). This communication occurs from the beginning of designing the product to the manufacturing processes with the right cost to delivery channels convenient to the customer and after-sale services. This communication will increase the profitability of the organisation and make the customers more loyal to the organisation's products and services.

Digital Transformation is all about continuous development. Therefore, applying Digital Transformation into the manufacturing processes will enhance the organisation's existing operations and make it less costly or reduce manufacturing time by enabling digital technologies that make complex manufacturing processes more comfortable to implement efficiently and effectively (Gökalp et al., 2017).

Implementing Digital Transformation will enable open innovation culture inside the organisation, especially inside the manufacturing processes, which focus on these enabling digital technologies (Ismagilova et al., 2019).

All the benefits mentioned above will lead to having a definite competitive advantage among the organisation competitors. If the organisation does not apply digital technologies, its rivals will do that and gain an advancement over it (Demirkan et al., 2016). Companies with high technologies often get ahead of the competitors, especially in the business-to-business market. Implementing Digital Transformation will make the organisation stagey stronger whichever it is type if it is differentiation or cost reduction or concentrated market (Bharadwaj et al., 2013; Horvath et al., 2018; Ismagilova et al., 2019).

The fundamental reason businesses exist is to make profits for their owners or shareholders, so any process or strategy applied inside the organisation aims to this underlying reason. Digital Transformation provides more profits to the shareholders of the organisation by increasing sales channels and making manufacturing processes more productive by reducing the operating cost or reducing the operations time (Fernández-Rovira et al., 2021).

\subsection{Digital Transformation and the manufacturing ecosystem}

No doubt that the manufacturing industry with its different sectors is one of the most complex industries regarding its ecosystem. That is because of the complexity of its supply chain with multiple suppliers' existence with different layers (De Carolis et al., 2018). The complexity also goes beyond that with the distribution channels of physical goods from direct to indirect distribution channels until the product reaches its end user (Ashrafian et al., 2019; Hartley \& Sawaya, 2019; Nwankpa \& Roumani, 2016; Zangiacomi et al., 2020).

Besides, the complexity comes from the product's internal value chain from the design to the manufacturing processes itself. Digital Transformation helps to make the connection between these networked parties much more comfortable and faster at the same time. When using advanced digital technologies to the link between those parties, this will allow the communication between the entire ecosystem in real-time (Ananyin et al., 2018; Holmström \& Partanen, 2014; Zangiacomi et al., 2020). This linkage also will have impacts on different parties or beneficiaries of the same product. In this section, the enhancement of the entire ecosystem provided by Digital Transformation implementation is shown.

The manufacturing company, which is in the heart of the ecosystem, is not only connected to its direct suppliers but also somewhat connected to tier 2 or even tier 3 of suppliers to enhance raw material quality and make their product more suitable for their customers (Bordeleau et al., 2020). Even more, most of the manufacturing companies have multiple suppliers that need to coordinate and manage carefully (Benitez et al., 2020; Schniederjans et al., 2020).

This complexity of suppliers should be managed jointly for the transportation and storage of raw materials through Supplier Relationship Management software using Internet of Things and Big Data analytics to ensure that there will be no shortage of raw materials for the manufacturing processes. So, this needs to be carefully managed and coordinated with the procurement department.

Using advanced Digital Transformation technologies in the organisation's manufacturing process like smart machine and robots/cobots through advanced robotics management will enhance the organisation's productivity and continuously develop its products and services (Demirkan et al., 2016).

Another critical aspect of manufacturing is the maintenance department. Digital twin technologies are now widely used in training purposes for that specific purpose. So, in urgent situations, the maintenance team will be ready to do the task in a short time and in the most effective way possible.

Another internal department is the product's design, through getting feedback from marketing research activities and listening to the needs of the customers, they can develop a product that suits the customers and in the same time feasibly manufactured and profitable. As said earlier, the Digital Transformation is a customer- 
centric approach, so hearing the voice of the customer is very important in developing the organisation products and services.

Moreover, the organisation has another affected party, as the physical markets or distributors of products. Again, things like Customer Relationship Management (CRM) and digital channels to communicate with direct or indirect customers.

From a product point of view, consider the example of an aircraft manufacturer. The manufacturer has multiple suppliers for different components, and these suppliers have another tier of suppliers that the manufacturer needs to manage. Besides, the manufacturer has many stakeholders affected by them directly like the airport's administration, travel agencies, and passengers. Other stakeholders that are indirectly affected include, for instance, the duty-free market, customs duty department, airport workers.

Therefore, if something happened to the aircraft that needs maintenance and the flight will be delayed, without the digital communication between different parties, this may lead to chaos in the airport gate, results in angry customers that are waiting inside the gate or inside the aircraft for hours.

With Digital Transformation, this delay may be communicated in real-time for passengers to wait inside the airport and enjoy its facilities instead of sticking inside the gate. This flexibility also will help the airport administration to send the maintenance team, which in case of the shortage of materials will communicate to the supplier to provide the tools needed through supplier relationship management. The maintenance team will also provide high-quality work quickly because they are well trained in such scenarios using digital twin technologies to the aircraft and fix it quickly. Another connected beneficiary is the duty-free markets which if they have this information, they will be more active to attract passengers to buy more products. This example shows how the Digital Transformation connects all the manufacturing firm stakeholders in real-time to maximise benefits for all of them (Ananyin et al., 2018).

\section{Research limitations}

There are several limitations. The research has been narrowed to be applied only in the manufacturing industry. This constraint was for consistency reasons, but future research in other industries will be of great importance. Another limitation lies, as illustrated in the conference papers in the research study, Digital Transformation is an essential subject in many disciplines is agreed. Simultaneously, this may mean that some of the paths or issues on the study agenda are already under consideration.

\section{Conclusion and implication for future research}

The study presented here aims to define, analyse, and update the literature on digital transformation currently available and present six main findings. In summary, Digital Transformation (DT) is a customer-centric mechanism that enables continuous improvement in the productivity of the manufacturing processes using advanced digital technologies such as cloud computing, Internet of Things, big data analytics, digital twin, in all aspects of the organisation. To date, most contributors have been academics from information systems. There is a diverse range of Digital Transformation examples in the literature, with some demonstrating benefits from applying the Digital Transformation process in the manufacturing industry. There are, however, some key barriers to the adoption of Digital Transformation; for instance, lack of training and the skills gap exists in the manufacturing industry in general. This paper summarised the most adopted digital technologies used in the Digital Transformation process, for instance, the Internet of Things (IoT) and Digital Twin.

The findings confirm that Digital Transformation solutions can bring a revolutionary benefit for the manufacturing organisations through increasing productivity and enhancing the customer's engagement.

The results and issues raised in this paper provide a valuable basis for further work to be focused upon. Digital Transformation is a concept of enormous potential significance for manufactures. It offers routes for companies to step up the value chain and leverage value-added business activities.

Nevertheless, as this paper has gone some way to demonstrate what is Digital Transformation, there is little guidance available for manufacturers in this situation. Indeed, the following research questions can be posed:

1. How to assess the readiness for Digital Transformation inside the manufacturing firm?

2. What is the connection between technology and business aspects to achieve successful Digital Transformation in the manufacturing industry?

3. What is the roadmap in the manufacturing industry from the policy level for a productive Digital Transformation?

4. investigating the relationship between DT and innovation and the implications of this transformation regarding sustainability. 


\section{References}

Agrawal, P., \& Narain, R. (2018). Digital supply chain management: an overview. IOP Conference Series. Materials Science and Engineering, 455(1), 012074. http://dx.doi.org/10.1088/1757-899X/455/1/012074.

Ananyin, V., Zimin, K., Lugachev, M., Gimranov, R., \& Skripkin, K. (2018). Digital organization: transformation into the new reality. Business Info, 2018(2), 45-54. http://dx.doi.org/10.17323/1998-0663.2018.2.45.54.

Anwer, N., Eynard, B., Qiao, L., \& Maropoulos, P. (2019a). Editorial for the special issue on 'smart manufacturing and digital factory.'. Proceedings of the Institution of Mechanical Engineers. Part B, Journal of Engineering Manufacture, $233(5), 1341$. http://dx.doi.org/10.1177/0954405419842412.

Anwer, N., Eynard, B., Qiao, L., \& Maropoulos, P. (2019b). Editorial for the special issue on 'smart manufacturing and digital factory.'. Proceedings of the Institution of Mechanical Engineers. Part B, Journal of Engineering Manufacture, $233(5), 1341$. http://dx.doi.org/10.1177/0954405419842412.

Ashrafian, A., Powell, D. J., Ingvaldsen, J. A., Dreyer, H. C., Holtskog, H., Schütz, P., Holmen, E., Pedersen, A. C., \& Lodgaard, E. (2019). Sketching the landscape for lean digital transformation. FIP Advances in Information and Communication Technology, 566, 29-36. http://dx.doi.org/10.1007/978-3-030-30000-5_4.

Bai, C., Dallasega, P., Orzes, G., \& Sarkis, J. (2020). Industry 4.0 technologies assessment: a sustainability perspective. International Journal of Production Economics, 229, 107776. http://dx.doi.org/10.1016/j.ijpe.2020.107776.

Benitez, G. B., Ayala, N. F., \& Frank, A. G. (2020). Industry 4.0 innovation ecosystems: an evolutionary perspective on value cocreation. International Journal of Production Economics, 228, 107735. http://dx.doi.org/10.1016/j.ijpe.2020.107735.

Berghaus, S., \& Back, A. (2016). Stages in digital business transformation: results of an empirical maturity study. In Mediterranean Conference on Information Systems (MCIS) (Vol. 22, pp. 1-17). Retrieved in 2021, March 5, from http://aisel.aisnet.org/mcis2016\%0Ahttp://aisel.aisnet.org/mcis2016

Bharadwaj, A., El Sawy, O. A., Pavlou, P. A., \& Venkatraman, N. (2013). Digital business strategy: toward a next generation of insights. MIS Quarterly: Management Information Systems, 37(2), 471-482. http://dx.doi.org/10.25300/MISQ/2013/37:2.3.

Borangiu, T., Trentesaux, D., Thomas, A., Leitão, P., \& Barata, J. (2019). Digital transformation of manufacturing through cloud services and resource virtualization. Computers in Industry, 108, 150-162. http://dx.doi.org/10.1016/j.compind.2019.01.006.

Bordeleau, F. E., Mosconi, E., \& de Santa-Eulalia, L. A. (2020). Business intelligence and analytics value creation in Industry 4.0: a multiple case study in manufacturing medium enterprises. Production Planning and Control, 31(2-3), 173-185. http://dx.doi.org/10.1080/09537287.2019.1631458.

Brennen, J. S., \& Kreiss, D. (2016). "Digitization" and "digitalization" are two conceptual terms that are closely associated and often used interchangeably in a broad range of literatures. This entry argues that there is analytical value in explicitly making a clear distinction between thes. In K. B. Jensen, R. T. Craig, J. Pooley \& E. W. Rothenbuhler (Eds.), The International Encyclopedia of Communication Theory and Philosophy (pp. 1-11). Chichester: Wiley. https://doi.org/10.1002/9781118766804.wbiect111.

Cachada, A., Barbosa, J., Leitao, P., Alves, A., Alves, L., Teixeira, J., \& Teixeira, C. (2019). Using internet of things technologies for an efficient data collection in maintenance 4.0. In Proceedings 2019 IEEE International Conference on Industrial Cyber Physical Systems (ICPS 2019) (pp. 113-118). New York: IEEE. https://doi.org/10.1109/ICPHYS.2019.8780217.

Castelo-Branco, I., Cruz-Jesus, F., \& Oliveira, T. (2019). Assessing Industry 4.0 readiness in manufacturing: evidence for the European Union. Computers in Industry, 107, 22-32. http://dx.doi.org/10.1016/j.compind.2019.01.007.

Chryssolouris, G., Mavrikios, D., Papakostas, N., Mourtzis, D., Michalos, G., \& Georgoulias, K. (2009a). Digital manufacturing: history, perspectives, and outlook. Proceedings of the Institution of Mechanical Engineers. Part B, Journal of Engineering Manufacture, 223(5), 451-462. http://dx.doi.org/10.1243/09544054JEM1241.

Chryssolouris, G., Mavrikios, D., Papakostas, N., Mourtzis, D., Michalos, G., \& Georgoulias, K. (2009b). Digital manufacturing: History, perspectives, and outlook. Proceedings of the Institution of Mechanical Engineers. Part B, Journal of Engineering Manufacture, 223(5), 451-462. http://dx.doi.org/10.1243/09544054JEM1241.

Cimini, C., Pinto, R., \& Cavalieri, S. (2017). The business transformation towards smart manufacturing: a literature overview about reference models and research agenda. IFAC-PapersOnLine, 50(1), 14952-14957. http://dx.doi.org/10.1016/j.ifacol.2017.08.2548.

Cozmiuc, D., \& Petrisor, I. (2018). Industrie 4.0 by siemens: steps made next. Journal of Cases on Information Technology, 20(1), 31-45. http://dx.doi.org/10.4018/JCIT.2018010103.

De Carolis, A., MacChi, M., Negri, E., \& Terzi, S. (2018). Guiding manufacturing companies towards digitalization a methodology for supporting manufacturing companies in defining their digitalization roadmap. In Proceedings of the 2017 International Conference on Engineering, Technology and Innovation: Engineering, Technology and Innovation Management Beyond 2020: New Challenges, New Approaches (ICE/ITMC 2017) (pp. 487-495). Institute of Electrical and Electronics Engineers. https://doi.org/10.1109/ICE.2017.8279925.

Demirkan, H., Spohrer, J. C., \& Welser, J. J. (2016). Digital innovation and strategic transformation. IT Professional, 18(6), 14-18. http://dx.doi.org/10.1109/MITP.2016.115.

Dombrowski, U., \& Fochler, S. (2018). Servitization as a key driver for digital transformation of manufacturing companies' spare parts service. In Proceedings of the 2018 IEEE International Conference on Service Operations and Logistics, and Informatics, SOLI 2018 (pp. 291-296). New York: IEEE. http://dx.doi.org/10.1109/SOLI.2018.8476713.

Drake, E. (2019). Digital transformation. In 37th International Conference on Thermal Treatment Technologies and Hazardous Waste Combustors (IT3/HWC 2019). Pittsburgh: Air and Waste Management Association. https://doi.org/10.1353/jvc.0.0011.

El Hamdi, S., Oudani, M., \& Abouabdellah, A. (2020). Morocco's readiness to Industry 4.0. Smart Innovation, Systems and Technologies, 146, 463-472. http://dx.doi.org/10.1007/978-3-030-21005-2_44. 
Fernández-Rovira, C., Álvarez Valdés, J., Molleví, G., \& Nicolas-Sans, R. (2021). The digital transformation of business: towards the datafication of the relationship with customers. Technological Forecasting and Social Change, 162, 120339. http://dx.doi.org/10.1016/j.techfore.2020.120339.

Frank, A. G., Dalenogare, L. S., \& Ayala, N. F. (2019). Industry 4.0 technologies: implementation patterns in manufacturing companies. International Journal of Production Economics, 210, 15-26. http://dx.doi.org/10.1016/j.ijpe.2019.01.004.

Gökalp, E., Şener, U., \& Eren, P. E. (2017). Development of an assessment model for industry 4.0: Industry 4.0-MM. Communications in Computer and Information Science, 770, 128-142. https://doi.org/10.1007/978-3-319-67383-7_10.

Hartley, J. L., \& Sawaya, W. J. (2019). Tortoise, not the hare: digital transformation of supply chain business processes. Business Horizons, 62(6), 707-715. http://dx.doi.org/10.1016/j.bushor.2019.07.006.

Hausberg, J. P., Liere-Netheler, K., Packmohr, S., Pakura, S., \& Vogelsang, K. (2019). Research streams on digital transformation from a holistic business perspective: a systematic literature review and citation network analysis. Journal of Business Economics, 89(8-9), 931-963. http://dx.doi.org/10.1007/s11573-019-00956-z.

Heavin, C., \& Power, D. J. (2018). Challenges for digital transformation-towards a conceptual decision support guide for managers Journal of Decision Systems, 27(Suppl. 1), 38-45. http://dx.doi.org/10.1080/12460125.2018.1468697.

Heikkila, M., Rattya, A., Pieska, S., \& Jamsa, J. (2016). Security challenges in small-and medium-sized manufacturing enterprises. In 2016 International Symposium on Small-Scale Intelligent Manufacturing Systems (SIMS 2016) (pp. 25-30). New York: IEEE. http://dx.doi.org/10.1109/SIMS.2016.7802895.

Holmström, J., \& Partanen, J. (2014). Digital manufacturing-driven transformations of service supply chains for complex products. Supply Chain Management, 19(4), 421-430. http://dx.doi.org/10.1108/SCM-10-2013-0387.

Horvath, D., Csontos, R. S., \& Szabó, R. Z. (2018). Management aspects of smart manufacturing. In Proceedings of the 22nd World Multi-Conference on Systemics, Cybernetics and Informatics (WMSCI 2018) (Vol. 2, pp. 168-172). International Institute of Informatics and Systemics. Retrieved in 2021, March 5, from https://www.scopus.com/inward/record.uri?eid=2-s2.085055857841\&partnerID $=40 \& m d 5=461 \mathrm{c} 7 \mathrm{fbdf} 9327 \mathrm{bec} 8 \mathrm{bab} 68 \mathrm{f} 165 \mathrm{~b} 48 \mathrm{c} 8 \mathrm{c}$

Ismagilova, L. A., Gileva, T. A., Galimova, M. P., Sitnikova, L. V., \& Gilev, G. A. (2019). The digital transformation trajectory of industrial enterprises. In Proceedings of the 33rd International Business Information Management Association Conference, IBIMA 2019: Education Excellence and Innovation Management through Vision 2020 (pp. 2033-2045). International Business Information Management Association. Retrieved in 2021, March 5, from https:/www.scopus.com/inward/record.uri?eid=2-s2.0$85074116005 \&$ partnerID $=40 \& \mathrm{md} 5=\mathrm{e} 0 \mathrm{a} 5 \mathrm{aeac} 3 \mathrm{e} 972 \mathrm{~b} 5 \mathrm{bff} 726660 \mathrm{~b} 7215549$

Kokolek, N., Jakovic, B., \& Curlin, T. (2019). Digital knowledge and skills: key factors for digital transformation. Annals of $D A A A M$ and Proceedings of the International DAAAM Symposium, 30(1), 46-53. $\mathrm{http} / / / \mathrm{dx}$.doi.org/10.2507/30th.daaam.proceedings.006.

Kolla, S., Minufekr, M., \& Plapper, P. (2019). Deriving essential components of lean and industry 4.0 assessment model for manufacturing SMEs. Procedia CIRP, 81,753-758. https://doi.org/10.1016/j.procir.2019.03.189

Kritzinger, W., Karner, M., Traar, G., Henjes, J., \& Sihn, W. (2018). Digital Twin in manufacturing: a categorical literature review and classification. IFAC-PapersOnLine, 51(11), 1016-1022. http://dx.doi.org/10.1016/j.ifacol.2018.08.474.

Kunii, Y., \& Hasegawa, T. (2019). Fujitsu's activities to support digital transformation. Fujitsu Scientific and Technical Journal, 55(1), 3-8. Retrieved in 2021, March 5, from https:/www.scopus.com/inward/record.uri?eid=2-s2.085061587212\&partnerID=40\&md5=c8ca5d87c9f6607f37418d00d7b9db08

Kutzner, K., Schoormann, T., \& Knackstedt, R. (2018). Digital transformation in information systems research: A taxonomy-based approach to structure the field. In 26th European Conference on Information Systems: Beyond Digitization - Facets of SocioTechnical Change, (ECIS 2018). Association for Information Systems. Retrieved in 2021, March 5, from https://www.scopus.com/inward/record.uri?eid=2-s2.0-85054933884\&partnerID=40\&md5=e4a72be6d291fb8f191b89dd1 da534af

Laird, K. (2017). Understanding the Digital Transformation Called Industry 4.0. Plastics Engineering, 73(1), 24-28. http://dx.doi.org/10.1002/j.1941-9635.2017.tb01637.x.

Lee, C., Leem, C. S., \& Hwang, I. (2011). PDM and ERP integration methodology using digital manufacturing to support global manufacturing. International Journal of Advanced Manufacturing Technology, 53(1-4), 399-409. http://dx.doi.org/10.1007/s00170010-2833-x.

Li, Y., Liu, C., \& Gao, J. (2018). Special issue on digital enterprise technologies in manufacturing. Proceedings of the Institution of Mechanical Engineers. Part B, Journal of Engineering Manufacture, 232(13), 2251-2252. http://dx.doi.org/10.1177/0954405418774602.

Loonam, J., Eaves, S., Kumar, V., \& Parry, G. (2018). Towards digital transformation: lessons learned from traditional organizations. Strategic Change, 27(2), 101-109. http://dx.doi.org/10.1002/jsc.2185.

Mittal, S., Khan, M. A., Romero, D., \& Wuest, T. (2019). Smart manufacturing: Characteristics, technologies and enabling factors. Proceedings of the Institution of Mechanical Engineers. Part B, Journal of Engineering Manufacture, 233(5), 1342-1361. http://dx.doi.org/10.1177/0954405417736547.

National Archives of Australia. (2011). Digital continuity plan. In 19th International Conference on Computer Applications in Shipbuilding (ICCAS 2019) (Vol. 1, pp. 1-13). London: Royal Institution of Naval Architects. Retrieved in 2021, March 5, from https://www.scopus.com/inward/record.uri?eid=2-s2.0-85074455236\&partnerID=40\&md5=51747f4e12df98a $8 \mathrm{~b} 7 \mathrm{a} 3343 \mathrm{e} 2 \mathrm{c} 28 \mathrm{bedf}$

Ng, H. Y., Tan, P. S., \& Lim, Y. G. (2019). Methodology for digitalization: a conceptual model. In 2018 IEEE International Conference on Industrial Engineering and Engineering Management (IEEM) (pp. 1269-1273). New York: IEEE. https://doi.org/10.1109/IEEM.2018.8607457.

Nwankpa, J. K., \& Roumani, Y. (2016). IT capability and digital transformation: a firm performance perspective. In 2016 International Conference on Information Systems (ICIS 2016). Dublin, Ireland. 
Osterrieder, P., Budde, L., \& Friedli, T. (2020). The smart factory as a key construct of industry 4.0: a systematic literature review. International Journal of Production Economics, 221, 107476. http://dx.doi.org/10.1016/j.ijpe.2019.08.011.

Paavola, R., Hallikainen, P., \& Elbanna, A. (2017). Role of middle managers in modular digital transformation: the case of Servu. In Proceedings of the 25th European Conference on Information Systems (ECIS 2017) (pp. 887-903). Guimarães, Portugal.

Paritala, P. K., Manchikatla, S., \& Yarlagadda, P. K. D. V. (2017). Digital manufacturing: applications past, current, and future trends. Procedia Engineering, 174, 982-991. https://doi.org/10.1016/j.proeng.2017.01.250

Parra, D. T., Angulo, L., Sandoval, J., \& Guerrero, C. D. (2019). Digital transformation in Colombia: An exploratory study on ICT adoption in organizations. In 2019 14th Iberian Conference on Information Systems and Technologies (CISTI). New York: IEEE Computer Society. https://doi.org/10.23919/CISTI.2019.8760608.

Peillon, S., \& Dubruc, N. (2019). Barriers to digital servitization in French manufacturing SMEs. Procedia CIRP, 83, 146-150). http://dx.doi.org/10.1016/j.procir.2019.04.008.

Piccinini, E., Hanelt, A., Gregory, R. W., \& Kolbe, L. M. (2015). Transforming industrial business: the impact of digital transformation on automotive organizations. In 2015 International Conference on Information Systems: Exploring the Information Frontier (ICIS 2015). Elsevier. Retrieved in 2021, March 5, from https://www.scopus.com/inward/record.uri?eid=2-s2.084964596864\&partnerID=40\&md5=a999f02e3572425f9c0403df979b9550

Qi, Q., \& Tao, F. (2018). Digital twin and big data towards smart manufacturing and Industry 4.0: 360 degree comparison. IEEE Access: Practical Innovations, Open Solutions, 6, 3585-3593. http://dx.doi.org/10.1109/ACCESS.2018.2793265.

Rojo Abollado, J., Shehab, E., \& Bamforth, P. (2017). Challenges and benefits of digital workflow implementation in aerospace manufacturing engineering. Procedia CIRP, 60, 80-85. http://dx.doi.org/10.1016/j.procir.2017.02.044.

Schallmo, D., Williams, C. A., \& Boardman, L. (2017). Digital transformation of business models-best practice, enablers, and roadmap. International Journal of Innovation Management, 21(8), 1740014. http://dx.doi.org/10.1142/S136391961740014X.

Schniederjans, D. G., Curado, C., \& Khalajhedayati, M. (2020). Supply chain digitisation trends: an integration of knowledge management. International Journal of Production Economics, 220, 107439. http://dx.doi.org/10.1016/j.ijpe.2019.07.012.

SME Media Staff. (2017). Rolls-Royce's PLM journey and growing digital transformation. Manufacturing Engineering, 159(3), 5557. Retrieved in 2021, March 5, from https://www.scopus.com/inward/record.uri?eid=2-s2.085032574223\&partnerID=40\&md5=94fa453dc95015784d645382f1651f6e

Tokody, D. (2018). Digitising the European industry: holonic systems approach. Procedia Manufacturing, 22, $1015-1022$. http://dx.doi.org/10.1016/j.promfg.2018.03.144.

Tolkachev, S. A., Bykov, A. A., Morkovkin, D. E., Borisov, O. I., \& Gavrilin, A. V. (2020). Digitalization of manufacturing in Russia, Belarus and the European Union. IOP Conference Series: Earth and Environmental Science, $421(3), 032041$. http://dx.doi.org/10.1088/1755-1315/421/3/032041.

Ulas, D. (2019). Digital transformation process and SMEs. Procedia Computer Science, 158, 662-671. http://dx.doi.org/10.1016/j.procs.2019.09.101.

Vial, G. (2019). Understanding digital transformation: a review and a research agenda. The Journal of Strategic Information Systems, 28(2), 118-144. http://dx.doi.org/10.1016/j.jsis.2019.01.003.

Zangiacomi, A., Pessot, E., Fornasiero, R., Bertetti, M., \& Sacco, M. (2020). Moving towards digitalization: a multiple case study in manufacturing. Production Planning and Control, 31(2-3), 143-157. http://dx.doi.org/10.1080/09537287.2019.1631468. 